\title{
Preparation of Titania Thick Films by Electrophoretic Sol-Gel Deposition Using Hydrothermally Treated Particles
}

\author{
Ryosuke SAKAMOTO, Hideki NISHIMORI, Masahiro TATSUMISAGO and Tsutomu MINAMI \\ Department of Applied Materials Science, College of Engineering, Osaka Prefecture University, 1-1, Gakuen-cho, Sakai-shi, Osaka 599-8531 \\ 水熱処理した粒子を用いたゾルーゲル電気泳動電着法によるチタニア厚膜の作製 \\ 坂本亮祐・西森秀樹・辰巳砂昌弘・南 努 \\ 大阪府立大学工学部機能物質科学科, 599-8531 大阪府堺市学園町 1-1
}

\begin{abstract}
Thick titania films were prepared by the modified electrophoretic sol-gel deposition method. The titania particles prepared by the sol-gel method were hydrothermally treated at $250^{\circ} \mathrm{C}$ under $5 \mathrm{MPa}$ and then calcined at $600^{\circ} \mathrm{C}$ in air. The particles crystallized by the hydrothermal treatment showed no aggregation during the calcination and were easily re-dispersed in a mixture of ethanol and water to form stable titania sol. Thick titania films of ca. $20 \mu \mathrm{m}$ in thickness were obtained on stainless steel sheets by electrophoretic deposition of the sol.

[Received March 30, 1998; Accepted July 13, 1998]
\end{abstract}

Key-words : Titania, Electrophoretic sol-gel deposition, Hydrothermal treatment, Thick film, Rutile, Anatase, Brookite

1. Introduction

We have successfully prepared thick silica films of ca. 20 $\mu \mathrm{m}$ in thickness by electrophoretic deposition of silica particles using the sols prepared by the sol-gel method. ${ }^{1)-5)}$ In the "electrophoretic sol-gel deposition method" silica particles were separated, if necessary, from the original sol and heat-treated at $600^{\circ} \mathrm{C}$ and then they were re-dispersed in an electrophoresis media such as an ethanol-water mixture for electrophoretic deposition. 4 ,5)

In recent years much attention has been focused on titania films because of their wide application in the fields of solar energy conversion, ${ }^{6)}$ self-cleaning photocatalysts, ${ }^{7)}$ gas sensors, ${ }^{8)}$ and so on. If thicker titania films are obtained easily, the application is expected to extend to waveguide, optical microlens, solid-state photoelectrochemical cell, etc. We have tried applying the electrophoretic sol-gel deposition method to prepare titania thick films. In a preliminary experiment, however, we found that the titania particles tended to aggregate in the heat treatment process and the re-dispersion of the particles was very difficult.

In the present study, hydrothermal treatment has been found to prevent the titania particles from aggregating and titania thick films were prepared by the electrophoretic solgel deposition using these hydrothermally treated particles.

\section{Experimental procedure}

Titania particles were prepared by hydrolysis of tetrabutylorthotitanate (TBOT, Wako Pure Chemical Industries, Ltd.). TBOT (33.4 g), distilled water (13.3 g), distilled ethanol (EtOH, $453 \mathrm{~g}$ ) and hydroxypropylcellulose (HPC, 0.500 g, Wako Pure Chemical Industries, Ltd.) were used as starting materials, the mole ratio of TBOT: $\mathrm{H}_{2} \mathrm{O}:$ EtOH being $1: 7.5: 100$.

HPC was dissolved in a half amount of EtOH, and then TBOT was added to the solution. Water and the rest of EtOH were mixed, and then the two solutions were mixed and stirred at $25^{\circ} \mathrm{C}$ for $17 \mathrm{~h}$. The titania particles formed in the solution were centrifuged and washed with EtOH by repeating the procedure of dispersion and centrifugation three times, and then washed with $\mathrm{H}_{2} \mathrm{O}$ in the same way. The particles were re-dispersed in $\mathrm{H}_{2} \mathrm{O}$ and hydrothermally treated at $250^{\circ} \mathrm{C}$ under $5 \mathrm{MPa}$ for $1 \mathrm{~h}$ in an autoclave. The hydrothermally treated particles were separated by centrifugation and vacuum-dried. The resultant particles were heat-treated in air at $600^{\circ} \mathrm{C}$ for $17 \mathrm{~h}$.

The sols for electrophoretic deposition were prepared in the following procedure. The heat-treated titania particles were re-dispersed in EtOH, and then added to a 1 mass \% ammonia water containing poly(acrylic acid) (PAA, $\mathrm{m} . \mathrm{w} .=450,000$, Aldrich Co.). The concentrations of titania and PAA were 1 and 0.1 mass $\%$ in the whole sol, respective1y. The mole ratio of EtOH : $\mathrm{H}_{2} \mathrm{O}$ was $8: 2$.

By applying dc voltage on the electrodes immersed in the sol, the particles electrophoresed to the anode to form a film. The anode as a coating substrate was stainless steel sheet (SUS430, $40 \times 25 \times 1.0 \mathrm{~mm}$ ) and the cathode as a counter electrode was spiral stainless steel wire (SUS304, $0.9 \mathrm{~mm}$ in diameter). Both electrodes were cleaned with $2-$ propanol in an ultrasonic bath before use. Constant dc voltage was applied to the electrodes using a power supply (Takasago, Ltd., GPV 0650-0.5). Voltage, current and electricity were monitored with an electronic voltmeter (TOA Dempa, PM-12), an electrometer (Takeda Riken Industry, TR-8651) and a coulometer (Nichia, N-CR646), respectively.

Differential thermal analysis and thermogravimetry (DTA-TG; Rigaku CN8078) were carried out for the particles. The phases of the particles were determined by Xray diffraction (XRD; Rigaku RINT 1100). Scanning electron microscopy (SEM; JEOL JSM-5300) was used for the observation of the particles and the films.

\section{Results and discussion}

Figure 1 shows the DTA and TG curves of titania particles washed with EtOH and vacuum-dried (without hydrothermal treatment, hereafter called as-prepared particles). The gradual weight loss is observed up to about $250^{\circ} \mathrm{C}$. This weight loss is due to evaporation of the solvent. Two exothermic peaks are observed at 250 and $450^{\circ} \mathrm{C}$ in the DTA curve. The latter, which is accompanied by slight weight loss in TG, is probably due to burning of residual organic groups.

Figure 2 shows the XRD patterns of particles for asprepared (a), heat-treated at $350^{\circ} \mathrm{C}(\mathrm{b})$, and heat-treated at $600^{\circ} \mathrm{C}$ (c), respectively. No diffraction peaks are observed in (a). However, the pattern (b) shows diffraction peaks due to anatase. Therefore the exothermic peak at $250^{\circ} \mathrm{C}$ in DTA (Fig. 1) is due to crystallization of anatase. The XRD 


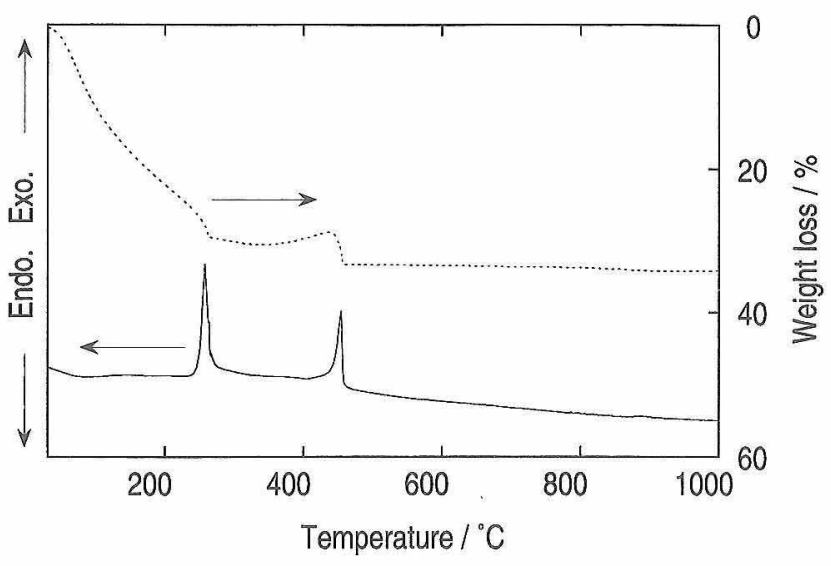

Fig. 1. DTA-TG curves of as-prepared titania particles.

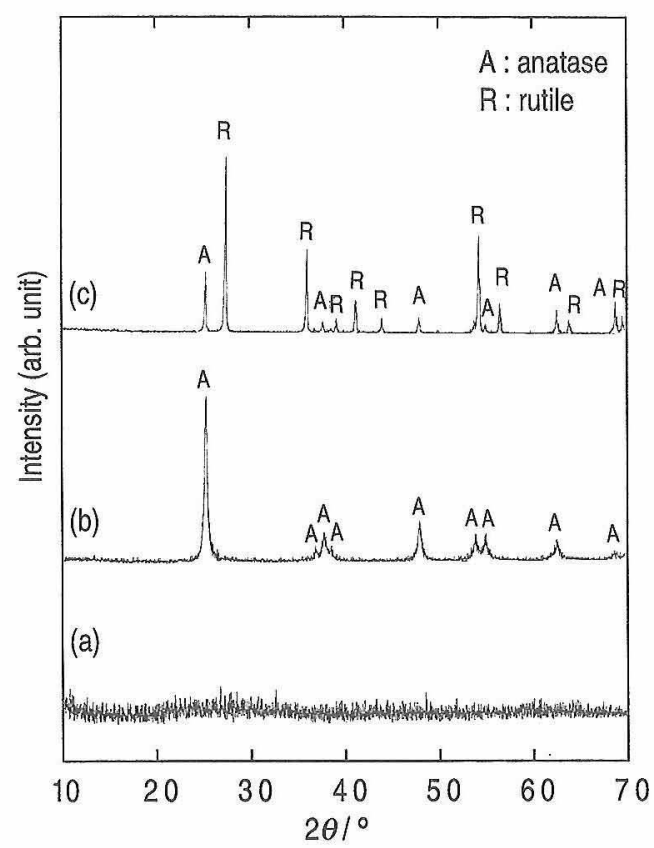

Fig. 2. XRD patterns of titania particles; (a) as-prepared, (b) heat-treated at $350^{\circ} \mathrm{C}$ for $17 \mathrm{~h}$ and (c) heat-treated at $600^{\circ} \mathrm{C}$ for $17 \mathrm{~h}$.

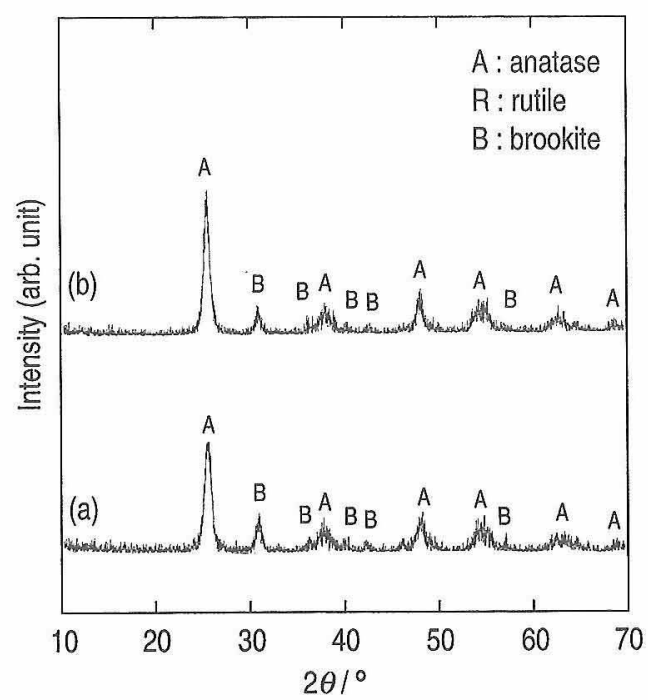

Fig. 3. XRD patterns of titania particles; (a) hydrothermally treated at $250^{\circ} \mathrm{C}$ for $1 \mathrm{~h}$ and (b) hydrothermally treated at $250^{\circ} \mathrm{C}$ and then heat-treated at $600^{\circ} \mathrm{C}$ for $17 \mathrm{~h}$. pattern of titania particles after the heat-treatment at $600^{\circ} \mathrm{C}$ shows that both anatase and rutile are present in the particles, indicating that the transformation from anatase to rutile occurs slowly. The transformation of anatase to rutile usually occurs at temperatures higher than $700^{\circ} \mathrm{C} .9$ )-11) In the present case, however, the transformation rate may accelerate probably by burning of residual organics.

For hydrothermally treated titania particles the XRD patterns are shown in Fig. 3; (a) is for as-treated particles and (b) for the particles after heat-treated at $600^{\circ} \mathrm{C}$. By the hydrothermal treatment, the crystallization of amorphous titania particles occurs to form mainly anatase and a small amount of brookite as shown in (a); the transformation of these phases to rutile does not occur after the heat treatment at $600^{\circ} \mathrm{C}$ for $17 \mathrm{~h}$ as shown in (b). DTA-TG curves of the hydrothermally treated titania particles showed no exothermic peak or weight loss. Since the residual organics were probably eliminated during the hydrothermal treatment, the lowering of the transformation temperature did not occur.

Figure 4 shows SEM photographs of (a) as-prepared and (b) hydrothermally treated titania particles, both of which were heat-treated at $600^{\circ} \mathrm{C}$ for $17 \mathrm{~h}$. The as-prepared particles aggregated in the heat treatment as shown in (a) and were not able to be re-dispersed to prepare sols for the electrophoretic deposition. The particles without hydrothermal

(a)

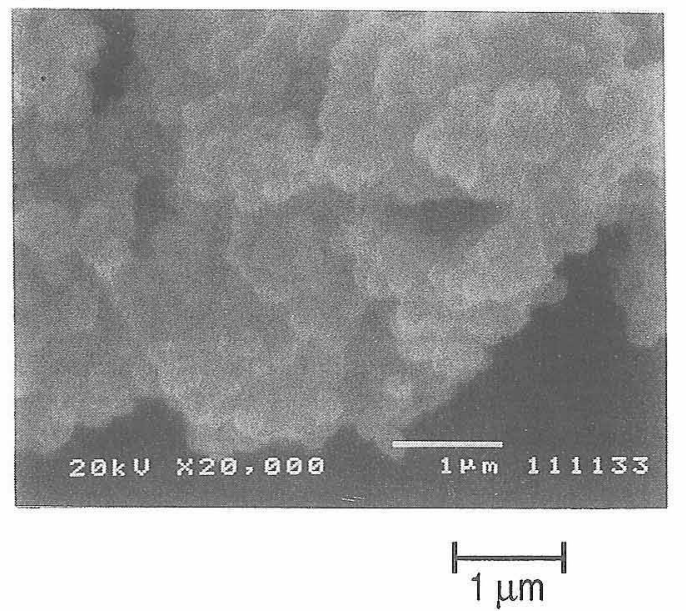

(b)

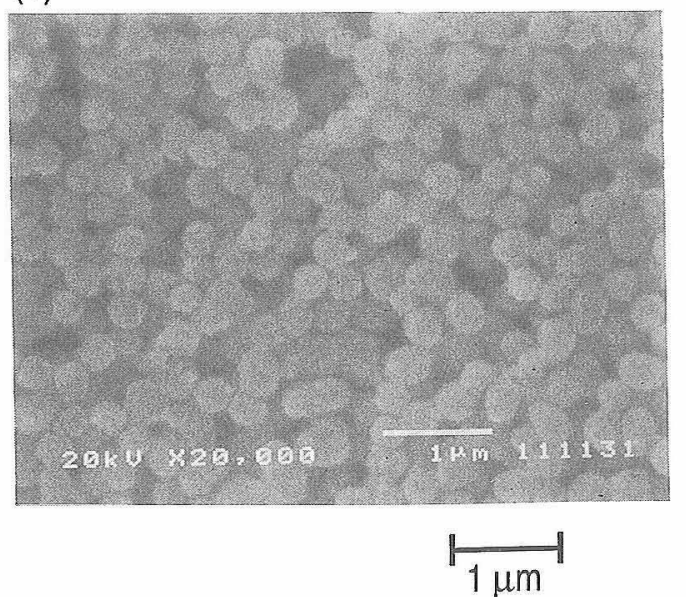

Fig. 4. SEM photographs of titania particles heat-treated at $600^{\circ} \mathrm{C}$ for $17 \mathrm{~h}$; (a) without hydrothermal treatment and (b) hydrothermally treated before the heat treatment. 
treatment apparently fuse together with one another from Fig. 4(a), indicating that the condensation reaction may occur among the particles. On the other hand, aggregation did not occur on the hydrothermally treated particles (b) since the surface of the particles are stabilized by the hydrothermal treatment not to react with one another by condensa-

(a)

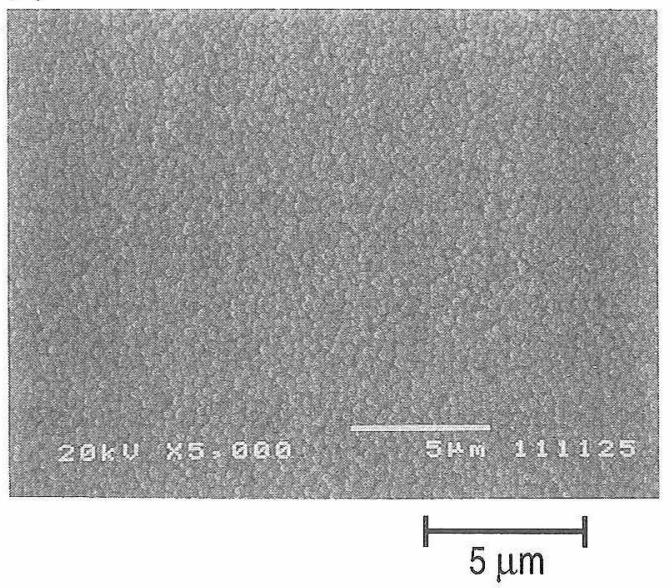

(b)

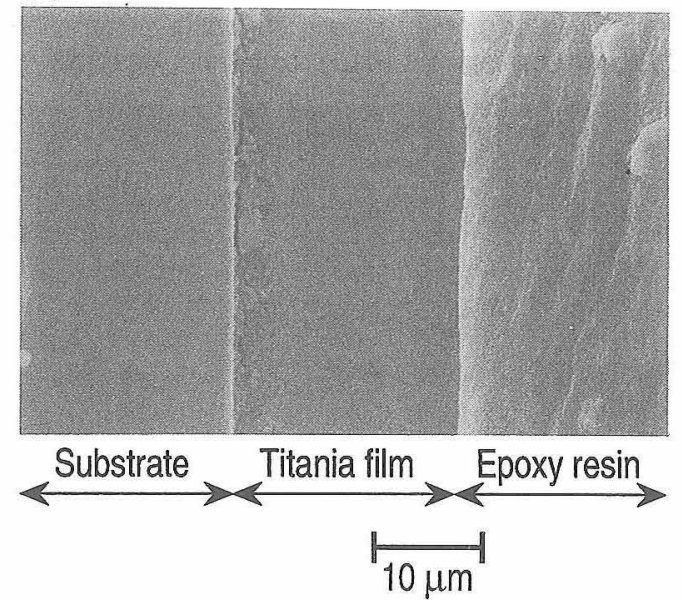

Fig. 5. SEM photographs of (a) surface and (b) cross section of a titania film. tion reaction. The diameter of the particles is ca. $0.3 \mu \mathrm{m}$, which is about the same as that of the as-prepared particles. The hydrothermally treated particles could easily be redispersed in EtOH even after the heat treatment and homogeneous sols were obtained.

Figure 5 shows SEM photographs of the surface (a) and cross section (b) of a titania film deposited on a stainless steel sheet by electrophoresis. The applied voltage was 20 $\mathrm{V}$ and the deposition time was $30 \mathrm{~min}$. The film consists of close-packed particles and no cracks are observed. Crackfree films of ca. $20 \mu \mathrm{m}$ in thickness were thus obtained.

\section{Conclusions}

The electrophoretic sol-gel deposition of hydrothermally treated titania particles was carried out. The titania particles were prepared by the sol-gel method, dispersed in water and hydrothermally treated at $250^{\circ} \mathrm{C}$ for 1 . The hydrothermal treatment prevented the particles from aggregating in the heat treatment process. Crack-free titania films of ca. $20 \mu \mathrm{m}$ in thickness were prepared on stainless steel sheets by electrophoresis of the hydrothermally treated and heat treated titania particles.

Acknowledgment This work was partly supported by a Grantin-Aid for Scientific Research from the Ministry of Education, Science, Sports and Culture of Japan.

\section{References}

1) H. Nishimori, M. Tatsumisago and T. Minami, J. Ceram. Soc. Japan, 103, 78-80 (1995).

2) H. Nishimori, M. Tatsumisago and T. Minami, J. Ceram. Soc. Japan, 103, 743-45 (1995).

3) H. Nishimori, K. Hasagawa, M. Tatsumisago and T. Minami, J. Sol-Gel Sci. Technol., 7, 211-16 (1996).

4) H. Nishimori, M. Tatsumisago and T. Minami, J. Mater. Sci., 31, 6529-34 (1996).

5) H. Nishimori, M. Tatsumisago and T. Minami, Bull. Chem. Soc. Japan, 69, 815-18 (1996).

6) B. O'Regan and M. Gratzel, Nature, 353, 737-39 (1991).

7) R. Wang, K. Hashimoto, A. Fujishima, M. Chikuni, E. Kojima, A. Kitamura, M. Shimohigoshi and T. Watanabe, Nature, 388, 431-32 (1996).

8) S. Kawai and T. Kawai, Kogyozairyo, 32[1], 64-67 (1984).

9) W. F. Sullivan and S. S Cole, J. Am. Ceram. Soc., 42, 127-33 (1959).

10) Y. Iida and S. Ozaki, J. Am. Ceram. Soc., 44, 120-27 (1961).

11) R. D. Shannon and J. A. Pask, J. Am. Ceram. Soc., 48, 39198 (1965) 